\title{
Hybrid solar-biomass system for district heating
}

\author{
Adrian Ilie ${ }^{1, *}$, and Ion Vișa ${ }^{1}$ \\ ${ }^{1}$ Transilvania University of Brasov, R\&D centre: Renewable Energy Systems and Recycling, 500464 Institutului 10, Brasov, Romania
}

\begin{abstract}
The energy used in the built-up environment represents at least $40 \%$ of the total energy consumed, out of which, at least $60 \%$ is required for heating, cooling and domestic hot water (DHW). Within the European Union, more than 6,000 communities (i.e. over 9\%) use district heating systems, the majority of which use the conversion of fossil fuels as a source of energy. This aspect, which is corroborated by the directives of the EU legislation on the use of renewable energy sources and energy performance, imposes the development of new solutions through which the existing district heating systems may be adapted to use renewable energy sources. The solar-thermal systems that are used on a large (district) scale are becoming more and more efficient from the point of view of their feasibility; however, it is almost impossible to create systems that should satisfy the thermal energy demand throughout the four seasons of the year. The hybrid solar-biomass system is becoming the applicable solution for the majority of the communities that have from this potential, since it can secure independence from the point of view of the use of thermal energy. This paper presents the design stages for the implementation of the hybrid solarbiomass systems with a view to identifying the optimal solutions for systems to be integrated into an existing district heating system. A case study (Taberei District in Odorheiu Secuiesc City), which provides a detailed description of the feasible technical solutions, is presented.
\end{abstract}

\section{Introduction}

The high consumption of energy in the built-up environment, together with the major climate changes and the low living standard represent 3 major issues that humanity is currently facing [1], and one of the potential remedies is the use of renewable energy sources for the development of sustainable communities [2].

The Conference of Parties (COP-21), through the ratified document (Paris Agreement), creates the opportunity for all the signatory countries (developed or developing countries) to make an equitable [3] and sustained [4] effort to maintain global warming under the limit of $2^{\circ} \mathrm{C}$ [5] and to continue the actions taken for the purpose of achieving the target of ,no greenhouse gas emissions" in developed countries and of reducing the level of harmful emissions in the developing countries, bearing in mind the national circumstances [6].

As a result of COP-21, a first instrument was created to generate examples of technological strategies and related methodologies [7], i.e. Deep Decarbonisation Pathways Project [8], in which 16 countries are involved in order to create personalised visions for meeting the "low-carbon world" objective.

The statistics show that the building stock of the European Union (EU) exceeds 24 billion $\mathrm{m}^{2}$ [9] (out of which, almost $75 \%$ represents the residential sector [10] with an average of $87 \mathrm{~m}^{2} /$ unit [11]) and that more than half of the EU population lives in areas that could benefit from at least one District Heating (DH) system [12]. Nevertheless, the current DH systems only provide $9 \%$ of the total demand [13], even though the individual systems are less efficient, more polluting and significantly more costly. This is due to a number of technical, technological, social and cultural factors [14]; therefore, the transition of the current systems into DH systems (that use renewable energy) must be based on/must create new concepts/technologies that take into consideration the existing built-up environment and the related equipment [15].

The need for the development of Hybrid SolarBiomass (HSB)systems has emerged from the need to identify a back-up solution for the Solar Thermal (ST) systems, which would use the conversion of renewable energies [16]. Currently, initiatives are registered around the world to integrate the HSB systems, most of which are still in the pilot stage, that of the development of the ST systems that would cover the (partial) demand of thermal energy, while the remaining demand would be covered by biomass conversion systems [17].

Denmark has built the greatest number of ST stations (using biomass conversion systems as back-up) and HSB stations for heating and DHW (over 50) [18], with capacities of up to $49 \mathrm{MW}_{\text {peak }}$ [19]. However, there are similar systems in Austria, Germany, France, Italy and Norway, with capacities between 1 and $7 \mathrm{MW}_{\text {peak }}$ [20].

The projects that have been developed so far involve the development of methodologies for HSB systems that provide thermal energy to the community by sizing the ST system [21], personalising/creating the DH system based on the possibilities of consumption/storage of solar energy [22] and the creation of a back-

*Corresponding author: adrian.ilie@unitbv.ro 
up/complementary system by integrating a biomass conversion system [23].

It is necessary to transform the existing DH systems into DH systems that include HSB systems, by breaking the technological [24] and financial [25] barriers, gradually identifying the implementation stages by using the available infrastructure [26] and by taking advantage of the local energy potential [27].

This paper describes the stages of the methodology, starting from the required energy consumption, the existing infrastructure and the solar-biomass ratio that is specific of the location of implementation. For purposes of exemplification, this paper presents a case study (Taberei District in Odorheiu Seuiesc City), which provides a detailed description of the feasible technical solutions.

\section{Method. Design stages.}

The proposed methodology is based on the interpretation of the data in the field regarding the existing infrastructure and the estimated or measured energy demand.

The methodology consists of the following stages:

- Stage 1: Input data;

- Stage 2: Designing the operation scheme;

- Stage 3: Assessment and optimisation of the operation through TRNSYS simulation;

- Stage 4: Designing the hybrid system.

\section{Stage 1: Input data}

The sizing of the components of production/distribution of the thermal energy is performed according to the specific national standards and it tends to oversize the installed capacities [28]. The collection of data from the location, based on a certain history (minimum 1 year) has major benefits, such as optimising the costs related to the installed capacities [29] and providing the possibility to personalise the technical solutions depending on the needs [30]. Thus, location-specific data shall be collected and identified as follows:

a) Weather data: Specific parameters of outdoor climate (outdoor ambient temperature; winter outdoor design temperature; humidity related to the outdoor ambient; intensity of the solar radiation; reference wind speed). Said parameters can be provided by a local weather station (ideally) or can be simulated by specialised software (e.g. Meteonorm) [31]. These data represent the input data for the energy simulation software and, regardless of the source, said information is relevant provided it have a frequency of at least 7.5 minutes (0.125 hours);

b) Technical parameters of the buildings (built-up area, useful area, insulation quality, positioning from the cardinal points etc.) can be measured or determined by classification into certain specific national standards (e.g. MC001/2006 in Romania [32]);

c) Number of consumers and the behaviour thereof (particularly with regard to the consumption of DHW);

d) The registered energy consumption represents the energy measured/invoiced history. It can replace the entry data (described at points b) and c) provided that there is a minimum 3-years history that can guarantee a high degree of reliability of the data;

e) Available infrastructure, consisting of the existing types of equipment/installations (pumping systems, ducts, storage systems etc.) that are available for the project.

\section{Stage 2: Designing the operation scheme}

By analysing the possibilities of implementing a HSB system, was designed an operation scheme (figure 1) using the TRNSYS Simulation Studio 17 software.

The operation scheme is based on the use of 4 thermal circuits (loops), out of which two are used to produce thermal energy (the solar collector circuit and the biomass boiler circuit) and two are used to distribute thermal energy (the heating circuit and DHW circuit), all of which are connected to each other as entries and exists, by means of a thermal energy storage tank. Herein under are the 4 circuits:

1. A solar-thermal collector circuit: is defined by the type of solar collector used, the type of heat exchanger used to isolate the main circuit (of the collectors) from the secondary circuit (of the energy storage tank) and the operation mode (admissible operation temperature for both circuits);

2. A biomass conversion boiler circuit: is defined by the type of boiler selected (with grates, fluidised bed etc.), but also by the operation mode, particularly when these types of boilers require significant intervals between starting and reaching the optimal operation parameters;

3. A thermal energy distribution circuit: is defined by the energy consumption related to the specific area. It is influenced by the outdoor temperature, the quality of the studied built-up environment and the related thermal energy distribution installations/ equipment. The heating circuit extracts the thermal energy from the energy storage tank through the action of a pump.

4. A DHW circuit: is defined by the energy consumption/the required hot water volume related to the number of residents and it mostly depends on the behaviour thereof. It consists of the main DHW production circuit that uses a heat exchanger and a pump that extracts thermal energy from the storage tank. The hot water is produced instantaneously (upon request), usually by means of some local substations. 


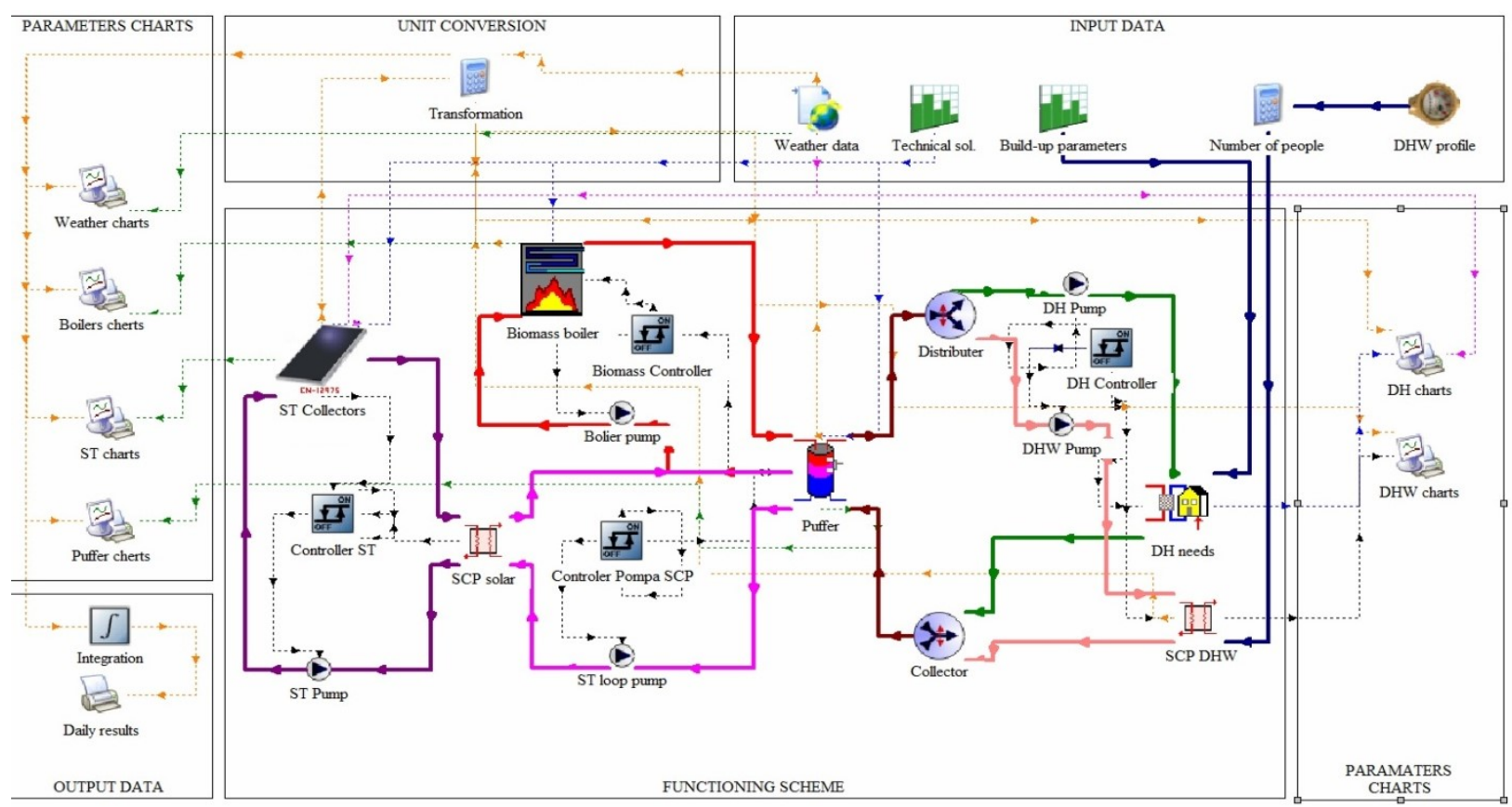

Fig. 1. Operation scheme using TRNSYS Simulation Studio 17.

\section{Stage 3: Assessment and optimisation of the operation by means of the TRNSYS simulation}

After designing the operation scheme, the support instruments for the correlation, interpretation and calculation of the data are defined in the TRNSYS software, bearing in mind the input data, as follows:

(i) Unit of measurement conversion processor: has the role of converting units of measurement into those used by the TRNSYS software to generate reports. This processor is used to convert all the energy-related units of measurement from $\mathrm{kJ} / \mathrm{h}$ into $\mathrm{kWh}$.

(ii) Chart generators for the output parameters have the role of converting each studied element into charts (the weather station, the biomass boiler, the solar thermal collectors, the storage tank, the heating system, DHW etc.);

(iii) Data integrator calculates and integrates the data provided by the software instantaneously and converts it into specific files (.xls, .txt, .dat) hourly, daily or annually.

The aim of the simulation is to identify the functionality and optimisation of the technical solution of implementation, by means of personalisation, while taking into account the consumption of thermal energy and the local energy potential.

\section{Stage 4: Designing the hybrid system}

The general concept is based on the need to use renewable energy sources (biomass and solar) in order to guarantee the heat and DHW demand throughout the year. A general operation scheme (figure 2) that is applicable based on the implementation characteristics of the location was designed for this purpose.
The general operation scheme of the hybrid system is based on the two thermal energy production circuits, i.e. the solar system circuit and the biomass conversion system circuit. Each circuit is equipped with its own pumping system and with heat exchangers for circuit isolation.

The thermal energy is provided by means of the two heat exchangers (SCP 1 and SCP 2) and it can be stored in the energy storage tank or it can be pumped directly into the DHW and heat exchangers, using the DC 2 distributor.

The heat exchangers are particularly used for the energy production loops, in order to extract all the available energy and to enable the exchangers to operate at high temperatures.

The storage circuit is equipped with its own pumping system and it can withhold a capacity between 1 and 50 $\mathrm{m}^{3}$. It consists of one or more containers that should comply with the indicated sizes and proportions in order to guarantee the stratification of the fluid stored based on the temperature.

The DHW and DH production circuits are equipped with heat exchangers and temperature adjustment valves, which are used based on the comfort requirements and the individual pumping systems.

The functionality of the system depends on the solar energy potential of the location. The operation principle is based on levels of priority, depending on the available energy, the energy demand and the storage capacities. The following operation cases were simulated:

a) Production of thermal energy in the ST system and distribution of the thermal energy for the production of DHW: This method of operation has the highest priority (because it is the most efficient) and it is based exclusively on the conversion of solar energy, which is transferred to the DHW production system, without passing through the storage system.

b) Production of thermal energy in the ST system for DHW production and storage of the surplus 
in the storage system: This system ranks second in the priority hierarchy and it involves the production of thermal energy in ST collectors, which is then transported to the DHW production system, while the surplus is stored in the provided storage tanks or it is exported to other systems.

c) Production of thermal energy in the ST system and additionally, in the biomass conversion system: This method of operation shall be used during times when there is not enough solar energy available (but there is still some energy input) and the difference that is required in order to cover the demand is produced by the biomass conversion system. This type of operation is based exclusively on the storage system, in which both systems shall discharge energy and from which, based on the demand, energy shall be extracted for the DHW production system and heat carrier production systems for $\mathrm{DH}$. stations) for each different section of the block of flats, which produce hot water and heating for stairwells and blocks of flats.

\section{Different scenarios}

The analysis of the possibilities of implementation of a hybrid system is based on the possibility of installing a solar thermal system and additionally, on the possibility of integrating systems that convert wood biomass into thermal energy. Thus, 4 potential scenarios were determined, as follows:

- $\quad \mathbf{1}^{\text {st }}$ scenario: Ensuring the energy demand for heat and DHW, by using biomass conversion boilers and taking into consideration the possibility of having to guarantee the DHW demand for 5 months, during the warm season;

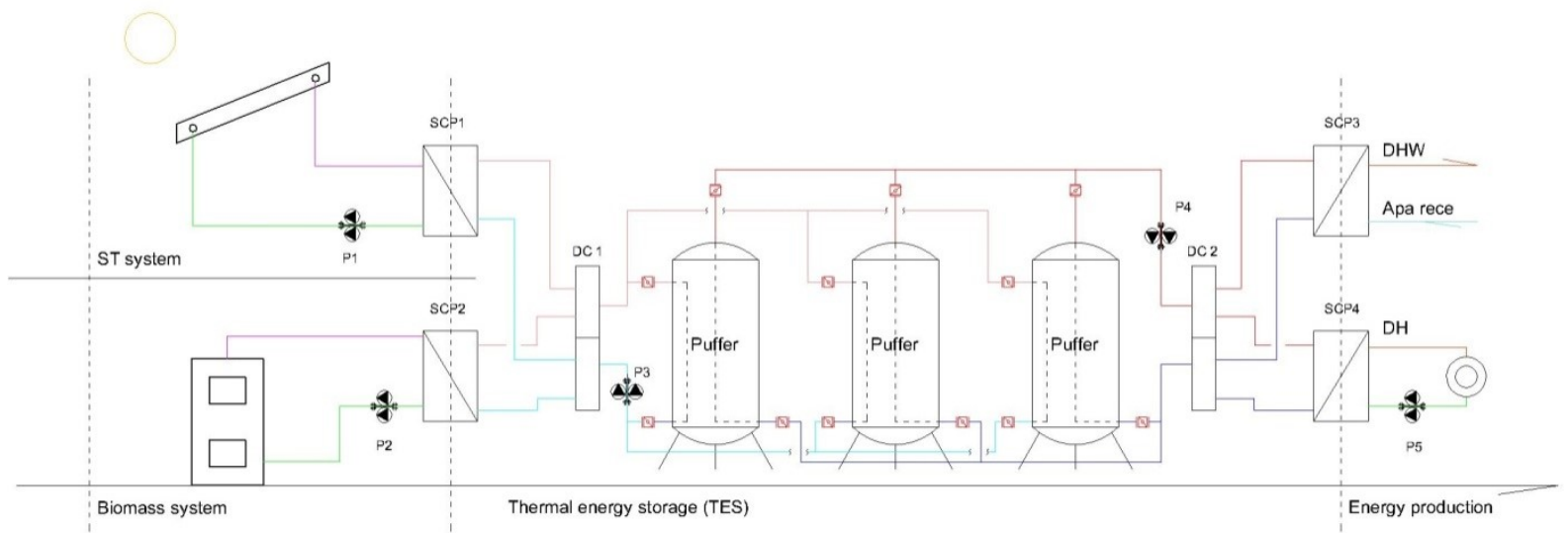

Fig. 2. General operation scheme of the HSB system.

d) Production of thermal energy exclusively in the biomass conversion system: This method of operation is considered the most disadvantageous and it is used when there is no solar energy available for production in the ST system. The production of energy in the biomass conversion system involves operation through the storage tanks, in order to balance the temperature variations generated by the fluctuating burning of the biomass.

\section{Case study. Results and discussion}

The case study involves the collective households in Taberei District of OdorheiuSecuiesc City, Harghita County, Romania.

The community (Taberei District) is located in the eastern side of the city $\left(46.3{ }^{\circ} \mathrm{N}\right.$ and $25.3^{\circ} \mathrm{E}$, at an altitude of $385 \mathrm{~m}$ above sea level), with a population of approximately 5,700 residents in 1496 flats. The district heating systems provides heat and DHW for 506 flats and 1950 residents, i.e. approximately $30 \%$ of the total number of potential users.

This district was selected for analysis because it has a retrofitted infrastructure of production and distribution of the heat carrier, which uses pre-insulated ducts installed underground with discharge in thermal modules (thermal
- $\quad 2^{\text {nd }}$ scenario: Ensuring the energy demand for heat and DHW, by using biomass conversion boilers and taking into consideration the possibility of having to guarantee the DHW demand for 6 months, during the warm season;

- $\quad 3^{\text {rd }}$ scenario: Ensuring the energy demand for heat and DHW, by using biomass conversion boilers combined with the use of the scheme regarding the possibility of having to guarantee the DHW demand for 5 months, during the warm season, with contribution to the heat carrier production installation;

- $\quad 4^{\text {th }}$ scenario: Ensuring the energy demand for heat and DHW, by using biomass conversion boilers combined with the use of the scheme regarding the possibility of having to guarantee the DHW demand for 6 months, during the warm season, with contribution to the heat carrier production installation;

\section{Stage 1: Input data}

The energy demand for heating was determined based on the methodology of calculation presented and it was compared to the data collected from the users' invoices, 
thus resulting in the data of the case study (509 flats, 1950 residents), which are provided in figure3.

By analysing the entry data, can notice significant differences between the calculated energy demand and the measured energy demand (e.g. approximately $20 \%$ for the heat demand), which leads, once again, to the recommendation of the sizing based on the on-site measured data.

The analysis of the energy distribution demand by month (figure 3) shows the fluctuations between the consumption during the cold season and the consumption during the warm season, which results in the need for sizing two systems that would operate seasonally, i.e. the ST system for thermal energy during the warm season and the biomass conversion system that generates additional energy for the ST system during the cold season.

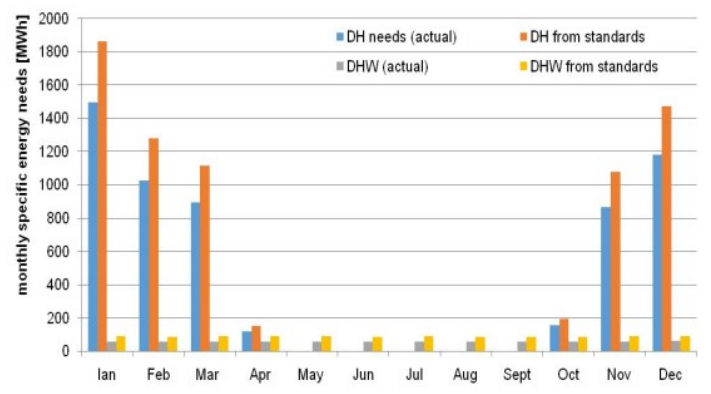

Fig.3. Energy demand for the case study.

\section{Stage 2: Designing the operation scheme}

The implementation options for the previously described scenarios (1-4) are based on the actual consumption of thermal energy for the production of heat and DHW. The monthly/daily distribution of energy consumption, together with the weather data provided by the Meteonorm software have been used as entry data for the simulations made in the TRNSYS Simulation Studio 17 software, with regard to the sizing and coverage of the energy demand. Subsequently, some technical solutions were generated (table 2):

Table 2. The technical solution for the hybrid system.

\begin{tabular}{|c|c|c|c|c|c|}
\hline \multirow{3}{*}{ 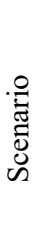 } & \multicolumn{2}{|c|}{ ST system } & Biomass system & \multicolumn{2}{|c|}{ Storage } \\
\hline & 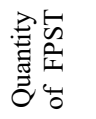 & $\stackrel{\mathscr{J}}{\grave{2}}$ & Technical solution & $\begin{array}{l}\stackrel{\Xi}{\Xi} \\
\stackrel{0}{0}\end{array}$ & 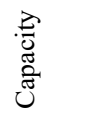 \\
\hline & [piece] & {$[\mathrm{m} 2]$} & {$[-]$} & {$[\mathrm{m} 3]$} & $\overline{[M W h]}$ \\
\hline 1 & 323 & 678 & $\begin{array}{l}2 \text { boilers } \times 2 \mathrm{MW} \\
+560 \mathrm{~m} 3 \text { storage }\end{array}$ & 60 & 8.47 \\
\hline 2 & 375 & 787 & $\begin{array}{l}2 \text { boilers } \mathrm{x} 2 \mathrm{MW} \\
+560 \mathrm{~m} 3 \text { storage }\end{array}$ & 70 & 9.88 \\
\hline 3 & 323 & 678 & $\begin{array}{l}2 \text { boilers } \times 2 \mathrm{MW} \\
+700 \mathrm{~m} 3 \text { storage }\end{array}$ & 100 & 14.11 \\
\hline 4 & 375 & 787 & $\begin{array}{l}2 \text { boilers } \times 2 \mathrm{MW} \\
+700 \mathrm{~m} 3 \text { storage }\end{array}$ & 120 & 16.93 \\
\hline
\end{tabular}

Regardless of the adopted technical solution, it is imperative to adapt the hybrid system to the existing systems, particularly for the storage systems, by converting the old hot water storage tanks, but also for the pumping and transport systems, by adapting them to the existing pumping stations and ducts.

For the purpose of this case study, was chosen the existing terrace of the district thermal station for placing the solar thermal panels. For the installation of the biomass conversion boilers was identified a location that belongs to the community, which is located near the district thermal station. The identified location (figure 4) was converted for placing the thermal stations and the biomass device.

In such case, the new thermal station has the role of producing and transporting the heat carrier to the existing thermal station, where, based on the demand, the heat carrier shall be used to produce heat and DHW or it shall be stored in the converted storage tanks.

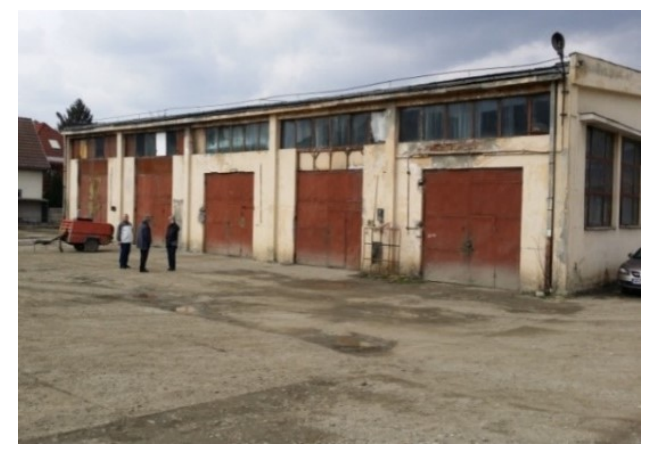

Fig.4. The location identified for the biomass station.

\section{Stage 3: The assessment and optimization of the functioning through TRNSYS simulation}

When designing the hybrid system, an analysis is made of the energy input supplied by the ST system that can be used during the periods when there is a heating demand, especially for the transition months (e.g. April and October).

For analysis purposes, the demand of energy for DHW and heating is considered globally, and the production of energy by the ST system has priority for the distribution to the end-users. Tables 3 and 4 present the demand distributions and the possibilities of energy production for the case study.

Through the use of the ST system, the adopted technical solutions provide the thermal energy needed for the production of DHW throughout the 5 months of the hot season (April 15 - September 15) for Scenario 3 (Table 3), respectively 6 months of warm season (April 1 - October 1). Both technical solutions have the advantage of supplying an input of thermal energy during the cold season as well, especially in transitional months (March and October).

Table 3. Production/demand distributions - Scenario 3.

\begin{tabular}{|c|c|c|c|c|c|}
\hline & \multicolumn{2}{|c|}{ Monthly demand } & \multicolumn{3}{|c|}{ Energy production } \\
\hline & & & \multicolumn{3}{|c|}{ Scenario 3 } \\
\hline Month & Inc. & DHW & Solar & Biomass & Surplus \\
\hline & {$[\mathrm{MWh}]$} & {$[\mathrm{MWh}]$} & {$[\mathrm{MWh}]$} & {$[\mathrm{MWh}]$} & {$[\mathrm{MWh}]$} \\
\hline
\end{tabular}




\begin{tabular}{|c|c|c|c|c|c|}
\hline Jan & 1498 & 58 & 7,40 & 1548,80 & - \\
\hline Feb & 1026 & 56 & 14,93 & 1068,18 & - \\
\hline Mar & 895 & 57 & 33,83 & 919,81 & - \\
\hline Apr & 119 & 56 & 55,49 & 120,38 & - \\
\hline May & - & 57 & 78,79 & - & 20,82 \\
\hline June & - & 56 & 84,98 & - & 28,55 \\
\hline July & - & 58 & 90,02 & - & 31,43 \\
\hline Aug & - & 55 & 77,59 & - & 22,19 \\
\hline Sept & - & 55 & 51,43 & 4,16 & - \\
\hline Oct & 156 & 56 & 35,53 & 177,46 & - \\
\hline Nov & 864 & 57 & 12,12 & 909,97 & - \\
\hline Dec & 1182 & 59 & 5,23 & 1236,41 & - \\
\hline
\end{tabular}

The differences of concept (Scenario 3 vs. 4) are determined by the size of the ST system (678 vs. $787 \mathrm{~m}^{2}$ solar collectors), which translates into different implementation costs and a different amount of produced energy. At the same time, for both scenarios we find that, during summer months (June to August), both systems produce surplus energy, which entails the necessity to store the surplus or to export it to other communities or to other industries (e.g. plant driers).

Table 4. Production/demand distributions - Scenario 4.

\begin{tabular}{|c|c|c|c|c|c|}
\hline & \multicolumn{2}{|c|}{$\begin{array}{c}\text { Monthly } \\
\text { demand }\end{array}$} & \multicolumn{3}{c|}{ Energy production } \\
\hline & & & \multicolumn{3}{c|}{ Scenario 4 } \\
\hline Month & Inc. & ACM & Solar & Biomass & Surplus \\
\hline & {$[M W h]$} & {$[M W h]$} & {$[M W h]$} & {$[M W h]$} & {$[M W h]$} \\
\hline Ian & 1498 & 58 & 8,20 & 1548,00 & - \\
\hline Feb & 1026 & 56 & 16,54 & 1066,56 & - \\
\hline Mar & 895 & 57 & 37,49 & 916,15 & - \\
\hline Apr & 119 & 56 & 61,49 & 114,37 & - \\
\hline May & - & 57 & 87,31 & - & 29,35 \\
\hline June & - & 56 & 94,18 & - & 37,76 \\
\hline July & - & 58 & 99,76 & - & 41,17 \\
\hline Aug & - & 55 & 85,99 & - & 30,59 \\
\hline Sept & - & 55 & 56,99 & - & 1,4 \\
\hline Oct & 156 & 56 & 39,37 & 173,61 & - \\
\hline Nov & 864 & 57 & 13,43 & 908,66 & - \\
\hline Dec & 1182 & 59 & 5,79 & 1235,84 & - \\
\hline & & & & & \\
\hline
\end{tabular}

Noting that any of the two selected scenarios can reach the required parameters, we recommend the use of the technical solution described in scenario 3 , because it has the advantage of the production of less surplus energy compared to scenario 4 and to the energy needed to produce DHW (e.g. in July a surplus of $31.43 \mathrm{MWh}$ energy is produced for scenario 3 vs. $41.17 \mathrm{MWh}$ for scenario 4, whereas the energy demand for DHW is 58 MWh).

\section{Stage 4: Designing the hybrid system}

Starting from the concept of the scheme in Fig. 2, an HSB system was designed and then integrated in the existing DH system. The four defined circuits (ST, biomass, DHW and DH) relate through the action of four $25 \mathrm{~m}^{3}$ storage tanks (converted from some former DHW accumulation tanks) that are located in the thermal station in Taberei District.

The ST circuit consists of 323 flat plane collectors $\left(2.1 \mathrm{~m}^{2}-\right.$ useful area) installed based on the azimuth angle $\left(\psi=0^{\circ}-\right.$ south exposure $)$ and the optimal tilt angle $\left(\chi=35^{\circ}\right)$ determined based on the maximum solar radiation plate solarthat can be collected all year round using a flat plate solar collector.

The biomass conversion circuit consists of two boilers with installed power $\left(2 \times 2 \mathrm{MW}_{\text {peak }}\right)$ that can operate simultaneously or alternatively. The minimum operating capacity of a boiler is $30 \%$ of the installed power, but the time required to reach the optimal operating parameters is at least 2 hours. During operation, the discharge of energy in the accumulation system and the determining of a consumption schedule (especially for transitional periods) is always necessary in order to secure predictability in the supply of thermal energy and to diminish energy losses.

In order to validate the results, the performance of the works related to the investment in scenario 3 was initiated, with the possibility of extension according to scenario 4.

The space made available through the integration of the biomass warehouse and of the boiler room as shown in Fig.5a... b was reconverted. Then the installation of the ST collectors was made as indicated in Figure 5c.

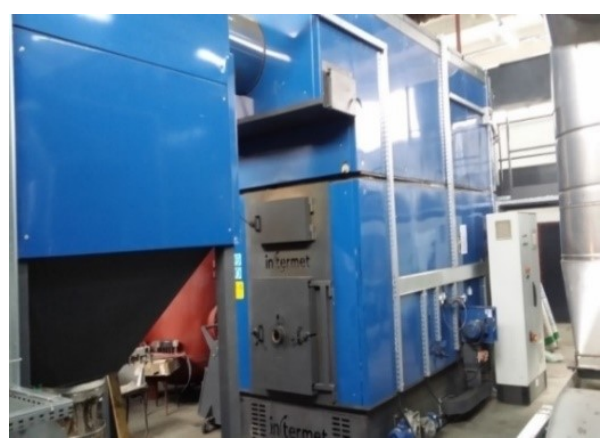

(a)

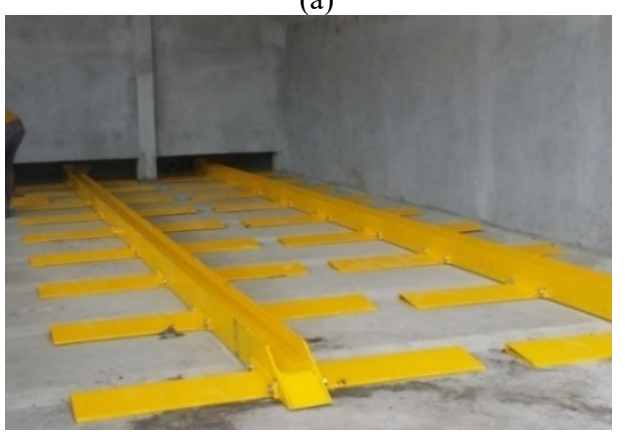

(b) 


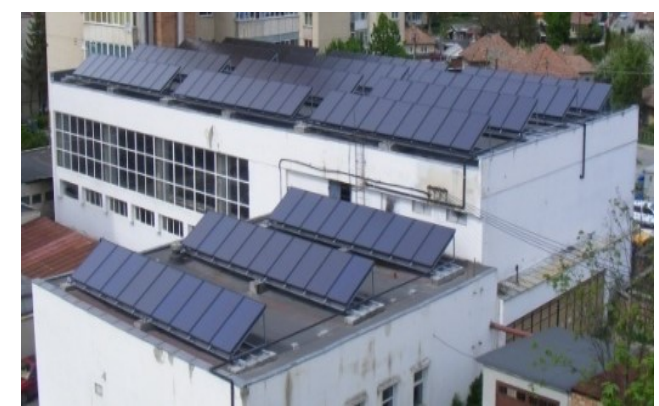

(c)

Fig. 6. Pictures taken during the implementation of the investment for the installation of the biomass conversion station (a) the boiler and (b) the biomass warehouse (c) the ST circuit.

The HSB system that has been recently developed and put into operation will offer data on the real solarbiomass ratio. The data collected throughout a year will contribute to the validation and optimization of the defined scenarios.

\section{Feasibility analysis}

Table 5 presents the analysis of the investment costs for the 4 defined scenarios based on the annual energy production, the annual energy consumption and the surplus of energy produced by the ST system.

The analysis of the data referring to profitability, taking into account an average sale cost of 5.5 eurocents $/ \mathrm{kWh}$ reveals a more than reasonable recovery time in the case of the biomass conversion systems (ranging between 7.32 and 7.61 years), which indicates the fact that any of the scenarios (1..4) chosen for the conversion of biomass is feasible. Moreover, by combining the solar-biomass systems, the investment recovery time stays within reasonable limits (between 7.88 and 8.83 years).

Table 5. Financial data of the possible scenarios.

\begin{tabular}{|c|c|c|c|c|c|c|}
\hline \multicolumn{3}{|c|}{ Scenario } & 1 & 2 & 3 & 4 \\
\hline \multirow{3}{*}{ 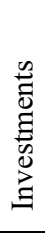 } & solar & [th. $\epsilon]$ & 303,7 & 357,2 & 358,4 & 416,2 \\
\hline & biomass & [th. $\epsilon]$ & 709,8 & 709,8 & 736,2 & 736,2 \\
\hline & total & [th. $\epsilon]$ & $1.013,5$ & 1.067 & $1.094,6$ & $\begin{array}{c}1.152 \\
4\end{array}$ \\
\hline \multirow{4}{*}{ 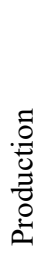 } & solar & {$[M W h]$} & 574 & 606 & 574 & 606 \\
\hline & biomass & {$[M W h]$} & 5.894 & 5.889 & 5.872 & 5.860 \\
\hline & surplus & {$[M W h]$} & 38,61 & 67,31 & 17,37 & 37,69 \\
\hline & total & {$[M W h]$} & 6.468 & 6.496 & 6.446 & 6.467 \\
\hline \multirow{3}{*}{$\begin{array}{l}\overrightarrow{0} \\
0 \\
0 \\
0 \\
0\end{array}$} & solar & [year] & 9,62 & 10,71 & 11,35 & 12,47 \\
\hline & biomass & [year] & 7,32 & 7,28 & 7,61 & 7,59 \\
\hline & total & [year] & 7,88 & 8,15 & 8,53 & 8,83 \\
\hline
\end{tabular}

\section{Conclusions}

The method proposed in this study allows the development of the best HSB system required to secure the thermal energy demand for the supply of DHW and DH throughout the year.

The proposed steps, the distinct functional situations and the scenarios proposed for the securing of the thermal energy needed to supply the DHW and DH allow the identification of the optimal operation of the HSB system.

The modelling of the functional situations using the TRNSYS software allows the asessment of the thermal energy demand (DH and DHW), the estimation of the solar energy potential and the simulation of the produced amount of thermal energy (solar-biomass) based on the demand and the potential.

The analysis of the feasibility of a HSB system shows that the recovery time is reduced up to $10 \%$ due to the use of some common storing/pumping installations.

\section{References}

1. M. Santamouris, Solar Energy 1, 61-94 (2016)

2. I. Visa, Anca Duta, Macedon Moldovan, "Outdoor performance of a trapeze solar thermal collector for facades integration”, Renewable Energy , 2018

3. CAT, Climate Action Traker (https://climateactiontracker.org/documents/352/CA T_BriefingNote_SB48_May2018.pdf) - accesed 22.06.2018

4. A. Izzet, R. Sari, Energy Strategy Reviews 18 175182 (2017)

5. R. Stavins, R. Stowe, The Paris Agreement and beyond: Internationa Climate Change Policy Post2020, (Cambridge, 2016)

6. UNFCCC, Adoption of the Paris Agreement, 2015. (https://unfccc.int/resource/docs/2015/cop21/eng/109 r01.pdf) -accesed 22.06.2018

7. S. Mathy, P. Menanteau, P. Criqui, Ecological Economics 150 273-289 (2018)

8. DDPP, Deep Decarbonization Pathways Project (http://deepdecarbonization.org/research-

methods/research-approach/) -accesed22.06.2018

9. ODYSSEE-MURE:(http://www.indicators.odysseemure.eu/online-indicators.html) $\quad$ - accessed 22.06.2018

10. Communication from the Commission to the European Parliament and the Council, Energy Efficiency and its contribution to energy security and the 2030 Framework for climate and energy policy, (Brussels, 2014) COM 2014/520.

11. P. Wegertseder, P. Lund, J. Mikkola, R. Alvarado, Solar Energy 135, 325-336 (2016)

12. A. Colmenar-Santos, E. Rosales-Asensio, D. BorgeDiez, J. Blanes-Peiró, Renewable and Sustainable Energy Review 62, 621-639 (2016) 
13. L. De Boecka, S. Verbekeb, A. Audenaertc, L. De Mesmaekerd, Renewable and Sustainable Energy Reviews 52, 960-975 (2015)

14. A. Ilie, I. Visa, A. Duta, Materials Science and Engineering, 147, 1-9 (2016)

15. European Solar Thermal Industry Federation (ESTIF), Solar termal contribution to the EU strategy for heating \& cooling, (Brussels, 2015)

16. A. Ilie, I. Visa, A. Duta, Journal of Energy Engineering (2017)

17. S. Guoa, Q. Liua, J. Sund, H. Jina, Renewable and Sustainable Energy Reviews 91, 1121-1147 (2018)

18. J. Nielsen, P. Sørensen, Renewable heating and cooling technologies and applications, 197-220 (2016)

19. M. Guadalfajara, M. Lozano, L. Serra, Solar Energy, 120, 72-86 (2015)

20. SDE (Solar District Heating) "Ranking list of European large scale solar heating plants" (2016)

21. R. Bet Sarkis, V. Zare, Energy Conversion and Management, 160 411-425 (2018)

22. U. Sahoo, R. Kumar, P. Pant, R. Chaudhary, Solar Energy, 139, 47-57 (2016)

23. C.M. Iftekhar-Hussain, B. Norton, A. Duffy Renewable and Sustainable Energy Reviews 68, 1115-1129 (2017)

24. I. Visa, A. Duta, Sustainable Energy in the Built Environment - Steps Towards nZEB, Springer Proceedings in Energy, 3-29 (Brasov, 2014)

25. T. van der Schoor, B. Scholtens, Renewable and Sustainable Energy Reviews 43, 666-675 (2015)

26. Z. Huang, H. Yu, Z. Peng, M. Zhao, Renewable and Sustainable Energy Reviews, 42, 1335-1348 (2015)

27. T, García-Álvarez, M. Moreno, I. Soares, Ecological Indicators, 60, 996-1007 (2016)

28. A. Ilie, I. Visa, Bul. of the Trans. Univ. of Braşov, Series I: Engineering Sciences 8(57), 79-86 (2015)

29. A. Ilie, I. Visa, A. Duta, Ann. of Dunarea de Jos Univ. of Galati, II, (2016)

30. B. Ganthiaa, S. Sasmitab, K. Routa, A. Pradhanc, J. Nayakd, Materials Today: Proceedings, 5, 220-225, (2018)

31. A. Buonomano, U. Montanaro, A. Palombo, S. Santini, Applied Energy, 163, 361-386 (2016)

32. MTCT, "Metodologie de calcul al performanţei energetice a clădirilor," [Methodology of computing the energy performance of buildings] (MC 001-1-23/2006, 2006). 